\title{
НАЦИОНАЛИЗМ VS ЕВРОПЕИЗМ В ПРЕДДВЕРИИ ВЫБОРОВ В ЕВРОПАРЛАМЕНТ
}

Аннотация. В статье рассмотрено поведение политических партий в преддверии выборов в Европейский парламент 2019 г. Выделена возросшая активность националистических сил в Европе, их стремление использовать в своих политических интересах экономические аргументы. Сделаны выводы об укреплении позищий наџионалистических партий и политических движений в странах ЕС и об увеличении в таких условиях их шансов на успех в европейских выборах. Прогнозируется укрепление позиций и увеличение числа мест начионалистов в будущем составе Европейского парламента.

Ключевье слова: политические силь, выборы, начионализм в экономике, суверенизм, наичиональные интересы, надначиональные органы, государство, интеграџия.

Как минимум за несколько месяцев до тех или иных выборов, в том числе европейских, различные политические силы, партии и движения стремятся использовать то или иное явление в стране и за её пределами в своих предвыборных интересах, и ситуация в экономике не является исключением.

Так, в феврале 2019 г. произошло, казалось бы, рутинное событие в хозяйственной деятельности, вызвавшее, с одной стороны, возмущение у руководства Франции, а с другой - получившее широкое одобрение политиков и профсоюзов в Нидерландах. Государство Нидерландов приобрело за 744 млн евро 14\%-ный пакет акций совместного с Францией авиаперевозчика Air France-KLM, практически уравняв свою долю в капитале этой авиакомпании с долей французского государства $(14,3 \%)$. Для правящей правоконсервативной коалиции во главе с премьер-министром М. Рютте этот шаг выглядит весьма выигрышно перед майскими 2019 г. выборами в Европейский парламент (ЕП).

Обозреватели французской газеты Монд назвали принятые правительством Нидерландов меры «биржевым блицкригом», напоминающим скорее технику рейдерского захвата, чем действия государства-акционера ${ }^{1}$. Министр экономики и финансов Франции расценил как «недружественный шаг» акцию нидерландского государства под предлогом «защиты национальных интересов». Добавим, что правительство Нидерландов предупредило французскую сторону о намерении провести эту операцию в самый последний момент. После случившегося акции авиаперевозчика Air France-KLM одномоментно подешевели на $11 \% 2$.

\footnotetext{
(ㄷ Клинова Марина Вилениновна - доктор экономических наук, ведущий научный сотрудник Центра европейских исследований, Национальный исследовательский Институт мировой экономики и международных отношений имени Е.М. Примакова РАН. Адрес: 117997, Россия, Москва, ул. Профсоюзная, д. 23. E-mail: marina.v.klinova @ gmail.com.

DOI: http://dx.doi.org/10.15211/vestnikieran22019125130

${ }^{1}$ Stroobants J.-P., Dutheil G. Air France-KLM: le raid boursier néerlandais vire à la crise politique. Le Monde, 28.02. 2019. URL: https://www.lemonde.fr/economie/article/2019/02/28/air-france-klm-le-raid-boursier-neerlandais-vire-a-lacrise-politique_5429348_3234.html (дата обращения: 12.04.2019).

${ }^{2}$ Dutheil G. «La France a tout intérêt à augmenter ses parts dans Air France-KLM». Le Monde, 28.02.2019. URL: https://www.lemonde.fr/economie/article/2019/02/28/la-france-a-tout-interet-a-augmente-ses-parts-dans-air-franceklm_5429476_3234.html (дата обращения: 12.04.2019).
} 
Те или иные, в том числе экономические действия, под лозунгом защиты национальных интересов, соответствующая риторика добавляют партиям националистического толка в Европейском союзе (ЕС) голоса избирателей. Такова, например, суверенистская линия, проводимая «Национальным объединением» во Франции, «Альтернативой для Германии» в ФРГ, партиями «Право и справедливость» в Польше или Союзом молодых демократов и «За лучшую Венгрию» в Венгрии и др. В том же ряду союз между «Лигой Севера» и «Движением 5 звёзд» в Италии, причём в этом случае можно говорить о победе на выборах националистических сил в одной из стран - основательниц Евросоюза - о победе с формированием кабинета министров. Можно прогнозировать дальнейшее укрепление суверенистского тренда и в ЕП, где национальные мотивы теснят «европейскую идею». На политическом поле национальная карта всё чаще разыгрывается и в контексте экономики.

Хотя французы владеют в Air France-KLM не 14, а 23\% голосов акционеров, благодаря закону Флоранжа ${ }^{1}$, в 2019 г. они неожиданно для себя оказались в положении японцев во франко-японском альянсе Renault-Nissan. В 2015 г. французское государство без согласования с японской стороной увеличило свою долю в капитале Renault. Ситуации схожи и тем, что в обоих случаях Франция вступала в кооперацию с иностранными компаниями, испытывавшими сложности на рынке.

За время существования альянсов партнёры Франции набирали силу и стали опережать французских коллег: 80\% чистой прибыли (net income) Air France-KLM сегодня даёт KLM ${ }^{2}$; Nissan по обороту почти вдвое опережает Renault. При этом каждый участник делового сотрудничества укрепил свои позиции на рынке, и в обоих случаях на разных уровнях было ясно заявлено, что распад альянсов не выгоден ни одному из партнёров: Renault-Nissan стал мировым лидером по выпуску легковых машин, Air France-KLM - с 2004 г. до последнего времени - многолетним лидером по авиаперевозкам Европы.

В обоих случаях резким шагам партнёров Франции (арест в Японии французского топменеджера Renault-Nissan и неожиданное приобретение государством Нидерландов дополнительного пакета акций в Air France-KLM) предшествовало объявление о намерении осуществить более тесную интеграцию компаний. Партнёры Франции опасались, что политика менеджмента, направленная на повышение эффективности и конкурентоспособности на рынке, косвенно могла бы привести к усилению влияния в альянсах французского государства. Именно этим воспользовалось правительство Нидерландов, выдвигая аргумент защиты национальных интересов. В двух конфликтных ситуациях налицо и существенное различие: в случае с Air France-KLM разногласия возникли уже между государствами, стоявшими у истоков европейской интеграции, учреждения Евросоюза. Это не помешало правящей в Нидерландах коалиции перед выборами в ЕП разыграть националистическую карту.

Вообще создание совместных компаний с участием государственного капитала изначально сопряжено с рисками, особенно в стратегических отраслях. Один из примеров - приобретение в 2011 г. для выхода на рынки Южной и Юго-Восточной Европы французской го-

\footnotetext{
1 Закон 2014 г., принятый в связи с закрытием там в 2012 г. завода металлургической компании ArcelorMittal, получил название города в департаменте Мозель. Согласно ст. L. 225-123, 124 Торгового кодекса и ст. 7 Закона, предусмотрено удвоение голосов акционеров, владеющих обыкновенными акциями свыше двух лет. Закон Флоранжа призван укрепить позиции акционеров, нацеленных не на краткосрочные спекулятивные доходы, а на долговременные прибыли, что обеспечивает устойчивое развитие предприятия и поддержание занятости. Loi $\mathrm{n}^{\circ}$ 2014-384 du 29 mars 2014. URL: https://www.legifrance.gouv.fr/affichTexteArticle.do;jsessionid=8016867873834A1 A4BD5A12DB03433DC.tplgfr35s_2?cidTexte=JORFTEXT000028811102\&idArticle=LEGIARTI000031012573\&dat eTexte=20140402 (дата обращения: 12.04.2019).

Air France-KLM's lost opportunity of 2018. 20.02.2019. URL: https://airinsight.com/air-france-klms-lostopportunity-of-2018/ (дата обращения: 12.04.2019).
} 
сударственной энергетической компанией $E D F$ итальянской Edison. Такое решение не получило поддержки тогдашнего правительства Италии, и оно инициировало закон, ограничивающий права доминирующего инвестора. Ранее, в 2006 г. схожая ситуация наблюдалась в энергетике: итальянская $E N E L$ (25,5\% капитала у государства) собралась приобрести компанию $S u e z$, которая в итоге досталась французской, тогда государственной, компании GDF. Именно в тот период во Франции получил хождение термин «экономический патриотизм».

Разногласия по экономическим вопросам зрели внутри интеграционного объединения на протяжении длительного времени и касались в том числе модели устройства Евросоюза и его ядра - еврозоны. Национализм набирает силу и в политике и в экономике. Партии и лидеры идут на выборы в Европарламент не как «еврофилы» или «еврофобы», а под лозунгом защиты национальных интересов - либо «против этой Европы», либо за ту Европу, которая будет защищать национальные (!) интересы. При этом конкурирующие на выборах в ЕП политические силы мало затрагивают саму тему «общеевропейского проекта», построения единой Европы, что нельзя считать случайностью.

Высший наднациональный орган исполнительной власти ЕС - Европейская комиссия (ЕК) - принимает порой решения, идущие вразрез с интересами европейских компаний. Пример тому - решение еврокомиссара по конкуренции Маргрете Вестагер (Дания) блокировать слияние французской Alstom и немецкой Siemens, которое бы привело к созданию «европейского чемпиона» по производству железнодорожного подвижного состава. Аргумент ЕК формальное нарушение правил конкуренции в ЕС - расчищает путь набирающим повсеместно мощь и завоёвывающим всё больше рынков китайским конкурентам, создающим промышленные гиганты при активной, если не сказать агрессивной, поддержке своего государства. В данном случае имеется в виду государственная локомотивостроительная корпорация КНР CRRC (China Railway Rolling Stock Corp.). Образованная в результате слияния в 2015 г. ранее конкурировавших между собой на международных рынках двух китайских государственных компаний CNR (China Northern Rolling Stock) и CSR (China South locomotive and rolling stock industry), CRRC превратилась в мирового лидера по производству железнодорожного оборудования. В противостоянии с европейскими наднащиональными органами национальные государства зачастую оказываются не в состоянии отстаивать свои и европейские интересы.

Символично, что именно сейчас опубликована книга с говорящим названием «Китай у ворот». Авторитетные французские аналитики из Европейского совета по международным отношениям (European Council on Foreign Relations, ECFR) предостерегают европейцев не от влияния культуры Китая, опасаются не за пресловутую «идентичность», а выражают обеспокоенность расширением влияния националистического «неокапитализма» китайского типа в лице мощного «государства-партии» (выделено мной - М.К.) - пока ещё второй в мире державы по экономической мощи (при сравнении объёмов ВВП в пересчёте на доллары США по валютному курсу, а по паритету покупательной способности - уже лидера). Европа открыта для китайских прямых инвестиций, товаров, услуг и ожидает того же от Китая. Однако в одиночку вести диалог с Китаем на равных не может уже ни одна из стран ЕС, даже наиболее развитая Германия. Вот почему приветствуется идея укрепления Европы как международного игрока ${ }^{1}$ и критикуются попытки отдельных стран (как поступила Италия - М.К.) развивать связи с Китаем на двусторонней основе, которые в любом случае не могут быть равноправными.

Свои опасения высказывает и ЕК в сообщении от 12 марта 2019 г., адресованном в том числе Европарламенту. Китай в этом документе определяется не только как «экономический

\footnotetext{
${ }^{1}$ Godement F., Vasselier A. La Chine à nos portes. Une stratégie pour l'Europe. P., Odile Jacob, 2018. P. 8-9, 11. Научно-аналитический вестник ИЕ РАН, 2019, №2
} 
конкурент», но и как «системный противник, продвигающий альтернативную модель управления» ${ }^{1}$. Парадокс ситуации состоит в том, что европейская наднациональная власть, правильно определяя суть проблемы, на практике принимает решения, снижающие конкурентный потенциал интеграционного объединения. Французский министр экономики и финансов также призвал ЕС «собрать все свои силы», осуществлять инвестиции, развивать инновации, создавать промышленных чемпионов, чтобы в конкурентной борьбе «противостоять Китаю и США» ${ }^{2}$.

Решение ЕК по Alstom и Siemens Франция назвала экономической и политической ошибкой. Собственно, под тем же углом зрения, но уже в контексте защиты экономических интересов США и их позиций на рынке энергоносителей в ущерб интересам ЕС, можно рассматривать мнение еврокомиссара и по газопроводу «Северный поток - 2»: утверждается, что этот проект якобы противоречит интересам Европы... На очереди вердикт ЕК по сделке между французскими судоверфями Saint-Nazaire и итальянской государственной судостроительной компанией Fincantieri. Эту сделку с учётом её масштабов в судостроении сравнивают с созданием Airbus в авиации. Неблагоприятен и нынешний политический фон - обострение межгосударственных отношений из-за позиции руководства Италии в отношении кризиса «жёлтых жилетов» во Франции вплоть до отзыва для консультаций посла Франции из Италии. Так что перед европейскими выборами ситуация в ведущих странах ЕС складывается пока в пользу расширения представительства в ЕП националистических партий и движений.

С учётом позиции нынешней ЕК остаётся открытым вопрос, как в Евросоюзе развивать высокие технологии в промышленности, модернизировать экономику, поднимать отсталые регионы, сокращать безработицу, если на наднациональном уровне создаются условия, в которых исключается, например, повторение такого высокотехнологичного достижения, как создание в ходе европейской кооперации концерна Airbus, составившего в авиастроении конкуренцию американскому Boeing.

В рамках ежегодно созываемого по инициативе Франции с 2013 г. собрания министров 24 европейских стран «Друзья промышленности» в декабре 2018 г., за несколько месяцев до выборов в ЕП в мае 2019 г., была принята декларация с обращением «восстановить суверенитет Европы» ${ }^{3}$. Тогда же министры экономики Франции и ФРГ подписали соглашение о сотрудничестве в трёх ключевых областях: создании в ЕС электробатарей (чтобы конкурировать с доминирующими на рынке азиатскими производителями), в прорывных инновационных технологиях, в создании искусственного интеллекта ${ }^{4}$. Эта цель в числе 15 приоритетных зафиксирована в ст. 21 Ахенского соглашения, дополняющего Елисейский договор 1963 г. между Францией и Германией 5 .

Партнёры в рамках форума «Друзья промышленности» потребовали, чтобы их програм-

\footnotetext{
${ }^{1}$ Joint Communication to the European Parliament, the European Council and the Council EU-China - A strategic outlook. Strasbourg, 12.03.2019. P. 1. URL: https://ec.europa.eu/commission/sites/beta-political/files/communication-euchina-a-strategic-outlook.pdf (дата обращения: 12.04.2019).

2 Bruno Le Maire: «La fusion Alstom-Siemens aurait permis d'investir massivement» - 1/5. La Tribune, 15.02.2019. URL: https://www.latribune.fr/economie/france/bruno-le-maire-la-fusion-alstom-siemens-aurait-permis-d-investirmassivement-807400.html (дата обращения: 12.04.2019).

${ }^{3}$ Les Amis de l'industrie: $6^{\text {eme }}$ réunion ministérielle. 21.12.2018. URL: https://www.entreprises.gouv.fr/secteursprofessionnels/amis-de-industrie-6eme-reunion-ministerielle (дата обращения: 12.04.2019).

${ }^{4}$ По оценкам экспертов, до 2030 г. только развитие систем искусственного интеллекта может добавить к ВВП стран ЕС свыше 10\% его текущего объёма. European Competitiveness and Industry. Benchmarking 2017. European Round Table of Industrialists. P. 24. URL: http://ert-industry-benchmarking.eu/wp-content/uploads/2017/12/ERTStats_Benchmarking-2017_4web_21122017hyperlinksgroupedBookmarks.pdf (дата обращения: 12.04.2019).

5 Traité entre la République française et la République fédérale d'Allemagne sur la coopération et l'intégration francoallemandes. P. 11. URL: https://www.diplomatie.gouv.fr/IMG/pdf/traite.aix-la-chapelle.22.01.2019_cle8d3c8e.pdf (дата обращения: 12.04.2019).
}

Научно-аналитический вестник ИЕ РАН, 2019, №2 
ма получила с первого полугодия 2019 г. статус европейского проекта общественной значимости и финансовую поддержку на уровне Евросоюза. Этими вопросами придётся заняться уже новому составу Еврокомиссии, сформированному после майских выборов в Европарламент 2019 г.

В преддверии выборов в Европарламент проблемы экономической мощи Китая, укрепления его позиций в промышленности стран Евросоюза, как и расхождение экономических интересов ЕС с США, в том числе в энергетике, всё больше занимают умы политиков, экономистов, бизнесменов. Существующие проблемы подводят к мысли: юридические правила в EC, которые ослабляют интеграционное объединение, нуждаются в корректировке с учётом новых реалий в мировой экономике. «Вынесение за скобки» этих реалий создаёт почву для дальнейшего укрепления в Европарламенте позиций националистов-суверенистов со всего Союза вплоть до возможного создания ими фракции внутри этого наднационального органа EC.

\section{Список литературы}

Air France-KLM's lost opportunity of 2018. 20.02.2019. URL: https://airinsight.com/air-franceklms-lost-opportunity-of-2018/

Les Amis de l'industrie: 6ème réunion ministérielle. 21.12.2018. URL: https://www. entreprises.gouv.fr/secteurs-professionnels/amis-de-industrie-6eme-reunion-ministerielle.

Bruno Le Maire: «La fusion Alstom-Siemens aurait permis d'investir massivement»-1/5. La Tribune, 15.02.2019. URL: https://www.latribune.fr/economie/france/bruno-le-maire-la-fusionalstom-siemens-aurait-permis-d-investir-massivement-807400.html.

Dutheil G. «La France a tout intérêt à augmenter ses parts dans Air France-KLM». Le Monde, 28.02.2019. URL: https://www.lemonde.fr/economie/article/2019/02/28/la-france-a-tout-interet-aaugmente-ses-parts-dans-air-france-klm_5429476_3234.html.

European Competitiveness and Industry. European Round Table of Industrialists,2017. 43 p.

Godement F., Vasselier A. La Chine à nos portes. Une stratégie pour l'Europe. Odile Jacob, Paris, France, 2018. 240 p.

Joint Communication to the European Parliament, the European Council and the Council EUChina - A strategic outlook. Strasbourg, 12.0.2019. $11 \mathrm{p}$.

Stroobants J.-P., Dutheil G. Air France-KLM: le raid boursier néerlandais vire à la crise politque. Le Monde, 28.02.2019. URL: https://www.lemonde.fr/economie/article/2019/02/28/air-franceklm-le-raid-boursier-neerlandais-vire-a-la-crise-politique_5429348_3234.html.

Traité entre la République française et la République fédérale d'Allemagne sur la coopération et l'intégration franco-allemandes. 22.01.2019. 13 p.

\section{References}

Air France-KLM's lost opportunity of 2018. 20.02.2019. URL: https://airinsight.com/air-franceklms-lost-opportunity-of-2018/

Les Amis de l'industrie: 6ème réunion ministérielle. 21.12.2018. URL: https://www. entreprises.gouv.fr/secteurs-professionnels/amis-de-industrie-6eme-reunion-ministerielle.

Bruno Le Maire: «La fusion Alstom-Siemens aurait permis d'investir massivement»-1/5. La Tribune, 15.02.2019. URL: https://www.latribune.fr/economie/france/bruno-le-maire-la-fusionalstom-siemens-aurait-permis-d-investir-massivement-807400.html.

Dutheil G. «La France a tout intérêt à augmenter ses parts dans Air France-KLM». Le Monde, 
28.02.2019. URL: https://www.lemonde.fr/economie/article/2019/02/28/la-france-a-tout-interet-aaugmente-ses-parts-dans-air-france-klm_5429476_3234.html.

European Competitiveness and Industry. European Round Table of Industrialists, 2017. 43 p.

Godement F., Vasselier A. La Chine à nos portes. Une stratégie pour l'Europe. Odile Jacob, Paris, France, 2018. 240 p.

Joint Communication to the European Parliament, the European Council and the Council EUChina - A strategic outlook. Strasbourg, 12.03.2019. 11 p.

Stroobants J.-P., Dutheil G. Air France-KLM: le raid boursier néerlandais vire à la crise politique. Le Monde, 28.02.2019. URL: https://www.lemonde.fr/economie/article/2019/02/28/air-franceklm-le-raid-boursier-neerlandais-vire-a-la-crise-politique_5429348_3234.html.

Traité entre la République française et la République fédérale d'Allemagne sur la coopération et l'intégration franco-allemandes. 22.01.2019. 13 p.

\section{Nationalism vs Europeanism Before the Elections to the European Parliament}

Author. Marina Klinova, Doctor of Science (Economics), Leading Researcher, Center for European Studies, the Primakov National Research Institute of World Economy and International Relations, Russian Academy of Sciences. Address: 23, Profsoyuznaya str., Moscow, Russia, 117997. E-mail: marina.v.klinova@gmail.com.

Abstract. The article considers the situation in the economies of the European Union countries before the European elections in 2019. The increased activity of nationalist forces in Europe, their intention to use the economic arguments for their political aims are highlighted. The cases illustrate the States' participation in the capital of largest industrial companies and the problems arising in this connection in interstate relations, on the one hand, and between States and the EU supranational bodies, on the other. The possible consequences of the disagreements for the international economic relations of the EU and its leading countries are named. The destructive role in some cases of the EU supranational bodies in strengthening European industrial potential in the face of other economic blocs and individual economic actors is emphasized. The aspiration of the leading EU countries to unite their efforts in bilateral and multilateral formats to maintain the competitiveness of European industrial enterprises in key areas of the economy is highlighted. Conclusions on strengthening the positions of nationalist parties and political movements in the EU countries and on increasing in such conditions their chances of success in European elections were made. Strengthening positions and increasing the number of nationalist seats in the next European Parliament are predicted.

Key words: political forces, elections, nationalism in the economy, sovereign, national interests, supranational bodies, the state, integration.

DOI: http://dx.doi.org/10.15211/vestnikieran22019125130 